\title{
Graduation Prospects of College Students with Specific Learning Disorder and Students with Mental Health Related Disabilities
}

\author{
Mary Jorgensen ${ }^{2}$, Jillian Budd ${ }^{2,3}$, Catherine S. Fichten ${ }^{1,2,3,4,5}$, Mai N. Nguyen ${ }^{2} \&$ Alice Havel $^{1,2,5}$ \\ ${ }^{1}$ Dawson College - Montreal \\ ${ }^{2}$ Adaptech Research Network \\ ${ }^{3}$ McGill University \\ ${ }^{4}$ Jewish General Hospital - Montreal \\ ${ }^{5}$ CRISPESH \\ Correspondence: Catherine Fichten, Dawson College, 3040 Sherbrooke St. West. Montreal, Québec, Canada H3Z \\ $1 \mathrm{~A} 4$
}

Received: December 22, 2017

Accepted: January 8, 2018

Online Published: January 9, 2018

doi:10.5430/ijhe.v7n1p19

URL: https://doi.org/10.5430/ijhe.v7n1p19

\begin{abstract}
This study's goal was to compare aspects related to academic persistence of two groups of college students with non-visible disabilities: 110 Canadian two and four-year college students - 55 with mental health related disabilities and 55 with Specific Learning Disorder (LD). Results show that students with mental health related disabilities were less likely to intend to graduate than students with LD. Students with mental health disabilities were also older, more likely to be female, to have worse personal circumstances and to feel more socially isolated on campus. They were also less likely to be enrolled in their first choice program or to be registered for campus disability related services than students with LD. Different variables predicted intention to graduate for the two groups. This is a key finding in helping students in these two groups successfully graduate, as they may have different academic, social, personal and accommodation needs. Recommendations are made about how to intervene to improve the academic persistence of students with mental health related disabilities. These include minimizing the fear of stigmatization and adopting a model where accommodations are based on students' unique needs rather than their diagnoses.
\end{abstract}

Keywords: Psychiatric disabilities, Learning disabilities, College studies

\section{Introduction}

Because the number of two and four-year college students with non-visible disabilities has increased dramatically during the past decade it is important to evaluate what happens to them once they enter college. Among the largest groups of such students are those with mental health related disabilities and those with learning disabilities. There is a considerable literature on students with learning disabilities. The literature on students with metal health related disabilities is much sparser. Campus professionals are quite familiar with students with learning disabilities. This is not the case of students with mental health related disabilities, even though there is substantial comorbidity between these two diagnoses. The purpose of the present study is to separate the two groups into students with only learning disabilities and students with only metal health related disabilities to provide information on similarities and differences between the two groups and to provide applied recommendations about how to help students with mental health related disabilities succeed.

\section{Literature Review}

The number of students with disabilities in North American colleges and universities has increased dramatically in the past few years (Snyder \& Dillow, 2012). This is primarily due to the large number of students with non-visible disabilities, such as mental health related disabilities (e.g., major depressive disorder, anxiety disorder, obsessive compulsive disorder) and Specific Learning Disorder (LD) (American Psychiatric Association, 2013) - two groups which take longer than students with visible disabilities to graduate (Knight, Wessel, \& Markle, 2016) and which make up some of the largest groups of students with disabilities on North American campuses (Ardell, Beug, \& Hrudka, 2016; Kim \& Lee, 2016).

Many students with LD have mental health comorbidities (Capozzi et al., 2008; Margari et al., 2013), and these 
students are well known to campus disability service providers. While there are numerous differences between students with only LD and those with only mental health related disabilities which can affect their academic success (McEwan \& Downie, 2013), both campus professionals and professors have less experience providing accommodations to students who have ONLY mental health related disabilities (Becker \& Palladino, 2016; Dong \& Lucas, 2016), even though professionals believe that accommodations would be helpful to these students (Venville, Street, \& Fossey, 2014). For example, accommodations needed by students with mental health related disabilities do not involve screen readers or spelling and grammar checkers - common accommodations for students with LD with or without mental health related disabilities. A better understanding of the differences can provide further insight about facilitating inclusion of students with mental health related disabilities in college.

\subsection{Student Characteristics and Registration for Campus Disability Related Services}

\subsubsection{Students with Mental Health Related Disabilities.}

Enrollment of students with mental health related disabilities in college has been increasing (Koch, et al., 2014). The percentage of these students in colleges and universities varies between 30\% and 50\% (Blanco et al., 2008; Eisenberg, et al., 2007); many of these students may have other comorbidities.

For example, a large scale American study showed that among college and university students aged 19 to 25, "almost half of college-aged individuals had a psychiatric disorder in the past year" (Blanco et al., 2008, p. 1429), although almost $30 \%$ had a psychiatric diagnosis of substance use disorder. Blanco et al. also reported that only $25 \%$ of students had sought treatment. This may be explained, to some extent, by the age of onset for most mental health related disabilities, such as schizophrenia, anxiety, and mood disorders, which is in the late teens and early twenties (Kay, 2010). However, other factors may also explain why such a small percentage of college and university students with a diagnosable psychiatric disorder seek treatment (e.g., Lyman et al., 2016).

Recent Canadian studies show that most college students with mental health related disabilities have an anxiety related disorder (Gosselin \& Ducharme, 2017). Consistent with this view, Holmes and Silvestri (2015) found, in a US sample of 1,195 , that $75 \%$ had a single diagnosis, with mood disorders being the most frequent followed by anxiety disorders. Substance abuse disorders only accounted for only $5 \%$ of all reported diagnoses. Among students with a diagnosis, $25 \%$ had a comorbid psychiatric diagnosis (the most common combination was a mood and anxiety disorder).

Students with mental health related conditions have difficulty succeeding (Eisenberg, et al., 2009). They often report difficulties such as having to overcome personal barriers and obstacles, such as medication side effects, poor attention and concentration, and the fluctuating nature of their illness (Mowbray, Bybee, \& Collins, 2001). Students also report obstacles such as lack of understanding of mental illness by their peers and professors, lack of services on campus, and stigmatization that may result from disclosing their illness (Fossey, et al., 2017; Lyman et al., 2016; Murphy, 2017). Nevertheless, few studies have examined the academic experiences of students with mental health related disabilities in post-compulsory institutions (Koch, Mamiseishvili, \& Higgins, 2014).

Students with mental health related disabilities are not as accustomed to dealing with professionals who provide academic accommodations as students with LD (Salzer, Wick, \& Rogers, 2008). For example, Collins and Mowbray (2005) investigated barriers that students with mental health related disabilities reported when seeking disability related services. The most common barrier was fear of disclosure, followed by lack of knowledge about the student's own disability and services available on campus, fear of being stigmatized, and the lack of appropriate resources to help them. Thus, it is not surprising that only about $10 \%$ of students with mental health related disabilities were registered for campus disability related services (Dong \& Lucas, 2013).

\subsubsection{Students with Specific Learning Disorder (LD)}

There are increasing numbers of North American students with LD attending two and four-year colleges after graduating from high school (McGregor, et al., 2016). For example, among two-year college students, a random sample of three Canadian colleges showed that $4 \%$ of the entire student body self-reported LD (Fichten et al., 2014a). There are actually many more students on campus with LD if one takes into account those who have chosen not to disclose their disability (McGregor, et al.; Wagner et al., 2005). There is a very substantial literature on students with $\mathrm{LD}$, with several journals specifically devoted to this topic.

LD is generally lifelong (Harrison \& Holmes, 2012), and students have typically received academic accommodations before entering college (DaDeppo, 2009). Thus, many students with LD have been accustomed to dealing with individuals who provide disability related academic accommodations. Nevertheless, other factors may explain why students with LD are more likely to register for disability related services than students with mental health related 
disabilities. Accordingly, Harrison and Wolforth (2012) found that $68 \%$ of Canadian disability service offices reported that most of the students $(25-75 \%)$ who request accommodations through their services have LD and/or Attention Deficit Hyperactivity Disorder (ADHD).

\subsection{Academic Persistence}

\subsubsection{Students with Mental Health Related Disabilities}

Reported persistence of students with mental health related disabilities in college differs markedly across studies. For example, reported graduation and persistence rates vary from 14\% (Kessler, Foster, Saunders, \& Stang, 1995) to 63\% (Koch et al., 2014). Discrepancies are due to sampling considerations, two and four-year college enrollment, and the length of follow-up (cf. Fichten, et al., 2014b; Knight et al., 2016).

A well-known model suggests that academic persistence in college (i.e., registration for at least one additional semester) is influenced by individual characteristics, pre-enrollment educational experiences and commitments as these relate to academic and social inclusion (Tinto, 1975, 1993). In this context, Koch et al. (2014) found that the majority of students with mental health related disabilities never participated in school sports or study groups, never joined school clubs, and never had informal meetings with faculty (social inclusion). The only aspect of social and academic inclusion for them involved meetings with academic advisors (academic inclusion). Of the three variables measured (meeting with academic advisors, faculty, study groups) only meetings with advisors was related to persistence.

\subsubsection{Students with Specific Learning Disorder (LD)}

Despite their large numbers, graduation rates of students with LD continue to lag behind those of students without disabilities (Wagner et al., 2005), although this discrepancy may disappear if the follow-up period is lengthy (Jorgensen, et al., 2005; Knight et al., 2016). Poorer academic outcomes may result from several factors in addition to difficulties with reading or writing, such as problems managing time (Smith, English, \& Vasek, 2002).

DaDeppo (2009) found that while intellectual growth and interest in ideas are important in predicting academic persistence of students with LD, social aspects of academic inclusion (e.g., developing relationships with faculty members) may be the more powerful predictor. It is also important to note that background characteristics, such as parental education, gender, race / ethnicity, and past academic achievement, did not significantly account for the variance in academic persistence in her study.

\subsection{Theory of Planned Behavior}

Ajzen's (2002) Theory of Planned Behavior proposes that behavior is influenced by the intention to carry out the behavior. In our study this is intention to graduate. According to the theory, behavioral intention and behavior are both predicted by attitude, subjective norms, and perceived behavioral control.

Attitude is a positive or negative evaluation of a behavior. For example, if students have a more positive attitude toward graduation, they may be more likely to intend to graduate. Subjective norms refer to the perceived social or peer pressure that students experience from people who are important to them, such as family members and close friends. The theory posits that the greater emphasis that significant others place on graduation the more likely students are to intend to graduate. Perceived behavioral control refers to perceptions of the ease or difficulty of successfully enacting the behavior (i.e., intention to graduate); this is related to both self-efficacy beliefs and perceived controllability. The greater students' perceived behavioral control, the more likely they are to actually carry out the behavior. For example, the stronger a student's belief that they have overall control over completing their program of study, the more likely they are to intend to graduate.

The Theory of Planned Behavior has been used to predict academic persistence and graduation of students with disabilities in general (Fichten et al., 2014b, 2016). In the present investigation it is used to predict intention to graduate among students with LD and those with mental health related disabilities.

\subsection{The Present Investigation}

We carried out a comparative study of students with LD and those with mental health related disabilities to further examine the role of academic and social inclusion, background variables, the Theory of Planned Behavior and other aspects found to be important for graduation of students with disabilities. Based on previous research, the hypotheses were:

1) Students with LD are more likely to intend to graduate than students with mental health related disabilities. 
2) Students with LD will be more likely to register for campus disability services than students with mental health related disabilities.

3) Given the differences in characteristics between the two groups, the predictors of intention to graduate will be different for the two groups.

\section{Method}

\subsection{Participants}

A total of 110 Canadian students, 55 with only a learning disability (i.e., no other disability) and 55 with only a mental health related disability (i.e., no other disability), were participants. They were drawn from our database derived from a larger investigation of graduation and academic performance of Canadian college students with diverse disabilities (Fichten et al., 2014b).

All students were enrolled in a two or four-year certificate, diploma or degree program. Participants self-reported either as having ONLY a mental health related disability or as having ONLY LD. We excluded students reporting another disability such as attention deficit hyperactivity disorder (ADHD), a hearing or a mobility impairment. Demographic information comparing the two groups of participants (age, gender, etc.) are provided in Table 1 in Results.

\subsection{Measures}

\subsubsection{Demographic Questions}

These include gender, age, and parental education. We also provided a list of 14 disabilities / impairments (i.e., totally blind; visual impairment not adequately corrected by wearing glasses or contact lenses; Deaf; hard of hearing / hearing impairment; speech / communication impairment; learning disability (LD) such as dyslexia; attention deficit hyperactivity disorder (ADHD); mobility impairment: wheelchair / scooter user; mobility impairment: use of a cane / crutch / walker; limitation in the use of hands / arms; chronic medical / health problem such as diabetes or Crohn's; mental illness / psychological / psychiatric disability; neurological impairment (e.g.; epilepsy; traumatic brain injury); autism spectrum disorder such as autism or Asperger's, and asked participants to self-identify as many as applied. Self-reporting one's disability was necessary in this cross-Canada study as access to students' diagnostic documentation was not feasible.

\subsubsection{School Related Questions}

Participants were asked about which school they attended, registration for campus disability services, type of institution attended (i.e., two or four-year), full-time or part-time student status, and field of study. Students were also asked whether they were registered in their first choice program.

\subsubsection{CEQ (College Experience Questionnaire) (Fichten, Jorgensen, Havel, \& Barile, 2006)}

This measure is available in the Appendix. It inquires about aspects which act as facilitators or barriers to academic success $(1=$ Much harder to $6=$ Much easier). Two subscales inquired about students' Personal Situation and School Environment (academic inclusion).

\subsubsection{Theory of Planned Behavior (Fichten et al., 2014b)}

Four subscales reflect Ajzen's (2002) Theory of Planned Behavior. This measure is available in Fichten et al. (2016). All subscales, except Attitude toward graduation, use a 6-point Likert scale (1=Strongly disagree to 6= Strongly agree). Intention to Graduate consists of 5 items (e.g., I intend to complete my program of study). Attitude is measured using 6-point Likert-like scales (e.g., good-bad). Intention to graduate is influenced by: (1) Attitude toward graduation ( 8 items: e.g., Completing my program of study will be: very rewarding to very punishing); (2) Subjective Norms related to graduation consists of 3 items (e.g., Most people who are important to me think I should complete my program of study); and (3) Perceived Behavioral Control over graduation consists of 4 items (e.g., I have complete control over completing my program of study).

\subsubsection{Self-Efficacy Questionnaire (Solberg et al., 1998)}

This measures how confident participants are that they could successfully carry out various behaviors on a 10-point Likert-type scale $(0=$ Not at all confident to $9=$ Very confident $)$. Two subscales evaluated Course Self-Efficacy $(7$ items: e.g., do well on exams, take good class notes) and Social Self-Efficacy (6 items: e.g., talk to your professors / instructors, participate in class discussions, talk with academic and support staff). 


\subsubsection{Campus Climate - Social Alienation (Wiseman, Emry, \& Morgan, 1998)}

This scale measures the degree to which a respondent feels alienated on campus (e.g., I find myself lonely and lost on this campus). The scale has a total of 4 items and is scored using a six-point Likert- scale (1=Strongly disagree to $6=$ Strongly agree).

\subsection{Procedure}

This investigation was part of a larger study (Fichten et al., 2014b). In spring 2010 we sent invitations to all current and former two and four-year college students with disabilities in our database who had participated in our previous research. Announcements were also emailed to discussion lists focusing on Canadian college students and to project partners.

The online measure took approximately 20 minutes and we offered a $\$ 20$ honorarium. Individuals who indicated interest were directed to a website where they read the information and consent form approved by the Dawson College Human Research Ethics Committee. Participants clicked on the 'continue' button to signal their agreement.

\subsection{Research Design}

Data analyses used include independent samples t-tests, Chi-square, Pearson correlation, and stepwise regression.

\section{Results}

\subsection{Similarities and Differences Between Groups}

Because there were no significant differences in either group between males and females on most measures, data from males and females were combined. Students with mental health related disabilities were significantly older $(M$ $=28.39, S D=8.51)$ than students with $\operatorname{LD}(M=24.36, S D=4.29), t(107)=3.11, p=.003$. There was no significant difference between the groups on parental education $(M=14 \mathrm{yr}$.). Chi-square tests on demographic characteristics of the two samples are presented in Table 1.

Table 1. Demographic characteristics of students with mental health related disability and LD

\begin{tabular}{|c|c|c|c|c|c|c|}
\hline & \multicolumn{2}{|c|}{$\begin{array}{l}\text { Mental Health Related } \\
\text { Disabilities }\end{array}$} & \multicolumn{2}{|c|}{ LD } & \multirow[t]{2}{*}{$\mathrm{X}^{2}$} & \multirow[t]{2}{*}{$\mathrm{p}=$} \\
\hline & $\mathrm{n}$ & $\%$ & $\mathrm{n}$ & $\%$ & & \\
\hline \multicolumn{7}{|l|}{ Gender } \\
\hline Female & 49 & $91 \%$ & 39 & $71 \%$ & 6.89 & 0.009 \\
\hline Male & 5 & $9 \%$ & 16 & $29 \%$ & & \\
\hline \multicolumn{7}{|l|}{ Registration for disability services } \\
\hline Yes & 39 & $71 \%$ & 52 & $95 \%$ & 10.75 & 0.001 \\
\hline No & 16 & $29 \%$ & 3 & $5 \%$ & & \\
\hline \multicolumn{7}{|l|}{ Full / Part-time Status } \\
\hline Full-time & 45 & $82 \%$ & 49 & $89 \%$ & 1.17 & 0.279 \\
\hline Part-time & 10 & $18 \%$ & 6 & $11 \%$ & & \\
\hline \multicolumn{7}{|l|}{ First Choice Program } \\
\hline Yes & 44 & $80 \%$ & 51 & $93 \%$ & 3.78 & 0.052 \\
\hline No & 11 & $20 \%$ & 4 & $7 \%$ & & \\
\hline \multicolumn{7}{|l|}{ Two and Four-Year Colleges } \\
\hline Two year college & 11 & $20 \%$ & 16 & $29 \%$ & 1.23 & 0.268 \\
\hline Four year college & 44 & $80 \%$ & 39 & $71 \%$ & & \\
\hline \multicolumn{7}{|l|}{ Field of Study } \\
\hline Social science & 17 & $31 \%$ & 17 & $31 \%$ & & \\
\hline Professional programs & 15 & $27 \%$ & 15 & $27 \%$ & & \\
\hline Arts and humanities & 11 & $20 \%$ & 8 & $15 \%$ & & \\
\hline Science \& Engineering & 7 & $13 \%$ & 8 & $15 \%$ & & \\
\hline Business & 4 & $7 \%$ & 3 & $5 \%$ & & \\
\hline Career / Technical & 1 & $2 \%$ & 2 & $4 \%$ & & \\
\hline Other & 0 & $0 \%$ & 2 & $4 \%$ & & \\
\hline
\end{tabular}


Table 2 presents means and t-tests. These show that students with LD had better CEQ Personal Situation, Social Alienation, and Social Self-Efficacy scores than students with mental health related disabilities. They also had higher Theory of Planned Behavior: intention to graduate and perceived behavioral control over graduation scores. T-tests show no significant differences between the two groups on: Course Self-Efficacy or CEQ School Environment or on Theory of Planned Behavior attitude toward graduation or subjective norms.

Table 2. Comparison of scores of students who have mental health related disabilities and students with LD

\begin{tabular}{lllllllll}
\hline & Group & $\mathrm{n}$ & $\mathrm{M}$ & $\mathrm{SD}$ & $\mathrm{t}$ & $\mathrm{df}$ & $\mathrm{p}=$ & $\mathrm{d}$ \\
\hline${ }^{1}$ Campus Climate - Social Alienation & Mental Health & 55 & 3.11 & 1.24 & 5.67 & 98 & .001 & 1.08 \\
& LD & 54 & 1.94 & 0.89 & & & & \\
CEQ Personal Situation & Mental Health & 55 & 3.22 & 0.87 & -6.25 & 107 & .001 & 1.20 \\
& LD & 54 & 4.21 & 0.78 & & & & \\
CEQ School Environment & Mental Health & 55 & 3.90 & 0.76 & -1.27 & 107 & .207 & 0.24 \\
& LD & 54 & 4.09 & 0.84 & & & & \\
Course Self-Efficacy & Mental Health & 55 & 6.10 & 1.28 & -0.89 & 107 & .376 & 0.17 \\
Social Self-Efficacy & LD & 54 & 6.35 & 1.64 & & & & \\
Theory of Planned Behavior & Mental Health & 55 & 5.65 & 2.04 & -3.59 & 107 & .001 & 0.69 \\
Intention to Graduate & LD & 54 & 6.94 & 1.70 & & & & \\
Attitude Toward Graduation & Mental Health & 55 & 5.27 & 0.77 & -2.28 & 107 & .025 & 0.43 \\
& LD & 54 & 5.59 & 0.73 & & & & \\
Pental Health & 55 & 2.02 & 0.76 & 0.01 & 107 & .993 & 0.00 \\
& LD & 54 & 2.02 & 0.96 & & & & \\
Subjective Norms & Mental Health & 55 & 3.95 & 1.00 & -3.16 & 108 & .002 & 0.60 \\
& LD & 55 & 4.98 & 0.72 & & & & \\
& Mental Health & 55 & 5.37 & 0.92 & 0.17 & 107 & .862 & 0.03 \\
& LD & 54 & 5.34 & 0.89 & & & & \\
\hline
\end{tabular}

${ }^{1}$ A lower score is better.

\subsection{Predicting Intention to Graduate}

\subsubsection{Students with Mental Health Related Disabilities}

Tinto $(1975,1993)$ and Koch et al. (2014) proposed that academic and social inclusion are most closely related to academic persistence. Consistent with their views and the Theory of Planned Behavior, we entered the three Theory of Planed Behavior predictors and CEQ School Environment, Social Alienation and Social Self-Efficacy scores.

Results in Table 3 indicate that only two variables entered the regression: subjective norms related to graduation, and CEQ School Environment. These variables were significant, $F(2,52)=8.87, p=0.001$, and together explain $25 \%$ of the variability in Intention to Graduate. Pearson correlations show that none of the other variables of interest were significantly correlated with Intention to graduate. 
Table 3. Summary for stepwise regression: Behavioral intention to graduate for students with mental health related disabilities and LD

\begin{tabular}{|c|c|c|c|c|}
\hline Variables Retained in Model & R-squared & $\beta$ & $\Delta \mathrm{F}$ & $\mathrm{p}=$ \\
\hline \multicolumn{5}{|l|}{ Mental health related disabilities } \\
\hline Subjective Norms Related to Graduation & 0.197 & 0.44 & 12.96 & .001 \\
\hline CEQ School Environment & 0.254 & 0.25 & 4.03 & .050 \\
\hline \multicolumn{5}{|l|}{ LD } \\
\hline Perceived Behavioral Control over Graduation & 0.195 & 0.44 & 12.61 & .001 \\
\hline Subjective Norms Related to Graduation & 0.294 & 0.33 & 7.18 & .010 \\
\hline Social Self-Efficacy & 0.359 & 0.27 & 5.08 & .029 \\
\hline
\end{tabular}

In addition, the negative role of Alienation on Campus is also highlighted in the results. Feeling alienated on campus was significantly correlated with weaker feelings of Social Self-Efficacy, $r(55)=-.63, p=0.001$, and less Perceived Behavioral Control over graduation, $r(55)=0.31, \mathrm{p}=0.021$.

4.2.2 Students with LD

We entered the same variables into a stepwise regression to predict intention to graduate of students with LD. Results in Table 3 indicate that three variables entered the regression: perceived behavioral control over graduation, subjective norms related to graduation, and Social Self-Efficacy. These variables were significant, $F(3,53)=9.35, p$ $=0.001$, and together explain $36 \%$ of the variability in intention to graduate

Due to shared variance, Campus Climate - Social Alienation, which correlated highly with Social Self-Efficacy $r(54)$ $=.526, p<.001$, and with Intention to Graduate $r(54)=-0.27, p=0.048$, did not add significantly to the model. As a result of the small sample size, some variables that correlated significantly with intention to graduate were excluded from the model: more favorable CEQ Personal Situation, $r(54)=0.41, p=0.002$, and greater Course Self-Efficacy, $r(54)=0.28, p=0.043$.

\section{Discussion}

\subsection{Differences Between Students with Mental Health Related Disabilities and Students with LD}

\subsubsection{Demographics and Personal Circumstances}

As reported by others, students with mental health related disabilities in our study, too, were significantly older than students without disabilities (St-Onge, Tremblay, \& Garneau, 2009) as well as students with LD. Also, as in other samples of college students (McEwan \& Downie, 2013), students with mental health related disabilities were more likely to be female than male. Students with mental health related disabilities reported experiencing less facilitating personal circumstances than students with LD. This may, in part, be explained by the personal barriers that students with mental health related disabilities have to overcome, such as the side effects of medication and the fluctuating nature of their disability (Mowbray et al., 2001), although there may be other factors that contributed to this result.

\subsubsection{School Related Aspects}

Our sample of students with mental health related disabilities were less likely to intend to graduate than students with LD. This confirmed Hypothesis 1. In addition, students with mental health related disabilities felt that they had less behavioral control over graduation (i.e., ease or difficulty of enacting the behavior, a concept related to both self-efficacy beliefs and perceived controllability). This may, in part, be due to the fluctuating nature of mental health related disabilities (Mowbray et al., 2001) over which students have little control.

Another important difference between the two groups was that students with mental health related disabilities reported lower social self-efficacy (e.g., feeling comfortable talking to professors and peers). They also felt more isolated on campus than students with LD. This is central, given the importance of social integration and inclusion to academic persistence (Tinto, 1975). One possible explanation for this is that students with mental health related disabilities must deal with the stigma associated with their disability (Storrie, Ahern, \& Tuckett, 2010).

\subsubsection{Registration for Campus Disability Related Services}

Students with mental health related disabilities were less likely to have registered for campus disability-related services, confirming Hypothesis 2. This may, in part, be due to stigma, as Belch (2011) found that stigma has a significant impact on whether or not students with mental health related disabilities will seek support on campus. 
These results may also be due to the fact that, as shown by St-Onge, Tremblay, and Garneau (2009), Canadian college students with mental health related disabilities knew little about disability related campus access services (32\%) and were unlikely to use the services available to them (7\%). The campus-based services students reported using most frequently in their study were educational support services, financial aid, and counseling.

Future studies need to investigate why students with mental health related disabilities do not register for disability related accommodations, such as preferential registration times, note takers, extended time for exams and assignments, and a quiet space to take exams. This may be due to lack of knowledge about the services that are available, to the fear of being stigmatized, fear of disclosure, or perceived lack of the resources that these students find helpful (cf. Collins \& Mowbray, 2005) It is also possible that students with mental health related disabilities did not receive the services that they needed in the past or that they had a bad experience with disability service providers, many of whom are unfamiliar with mental health related disabilities (St-Onge, Tremblay, \& Garneau, 2009).

\subsection{Academic Persistence}

Intention to graduate, a component of Ajzen's (2002) Theory of Planned Behavior, was used as the predicted variable. Consistent with Hypothesis 3, The two groups had different predictors of intention to graduate, with the exception of subjective norms related to graduation, which was common. Facilitators and obstacles in the school environment also predicted intention to graduate among students with mental health related disabilities, while social self-efficacy and perceived behavioral control over graduation also predicted intention to graduate among students with LD.

\subsubsection{Students with Mental Health Related Disabilities}

Although a direct comparison is difficult because of differences in the way the concepts are measured, our findings are only partially consistent with those of Koch et al. (2014) and Tinto et al. (1975, 1993). For example, Koch et al. found that academic and social integration were most directly related to academic persistence. We found that while academic inclusion (CEQ School Environment in our study) predicted intention to graduate, social inclusion (Campus Climate - Social Alienation and the Social Self-Efficacy measure in our study) did not. Thus, in our study whether or not a student participated in study groups, school clubs, had informal meetings with faculty, or met with academic advisors (cf. Koch et al.) did not influence intention to graduate. Instead, the most powerful predictor of intention to graduate was subjective norms (i.e., views of friends and family) related to graduation.

\subsubsection{Students with LD}

For these students the two most powerful predictors of intention to graduate are based on Ajzen's (2002) Theory of Planned Behavior (i.e., the degree of control that students felt they had over graduation and the significance that people important to them put on completing their program of study), followed by social self-efficacy (e.g., talking with professors, participating in class discussions) - an aspect related to Tinto's (1975) views about social integration. Our findings reflect the results of DaDeppo (2009), who also found that close personal relationships with faculty members was a powerful predictor of academic persistence. In addition, feeling less alienated on campus was also significantly and positively related to intention to graduate, although this did not enter the regression.

\subsection{Synthesis}

A key difference between students with mental health related disabilities and those with LD is that the most powerful predictors of intention to graduate were subjective norms and how much control students felt that they had over whether or not they graduated, respectively. Thus, students with mental health related disabilities seem to be more influenced by how people important to them feel about them graduating; students with LD seem to be more strongly influenced by the control they feel they have over whether or not they will graduate. This difference has important implications for increasing the academic persistence of these two groups of students. It is also important to note that among students with mental health related disabilities who felt less alienated on campus reported greater social self-efficacy and more control over whether or not they will graduate. This is a key finding as it also reflects the struggle that students with mental health related disabilities report with social inclusion (Koch et al., 2014).

\subsection{Limitations}

Volunteer effects, self-selection biases, recruitment through e-mail discussion lists and the offices of disability service providers set limitations on the generalizability of the results. Yet, in an ongoing investigation of a random sample of 1384 two-year college students, results how that only 11 students with mental health related disabilities had registered for disability related services, while 49 did not, compared to 56 students with LD (with or without 
attention deficit disorder) who did not register and 89 who did. Students in the present study also self-reported their disabilities / impairments; therefore there is no confirmation of these diagnoses. Furthermore, the relatively small sample sizes limit the power of the statistical analyses. It is also important to note that our study was conducted in Canada, which does not have the same regulations as the American with Disabilities Act.

\subsection{Conclusions and Applied Recommendations}

Ways to improve conditions for students with LD are readily available (e.g., DaDeppo, 2009; Wagner et al., 2005). Service providers are struggling to provide support services and accommodations to the increasing number of students with mental health related disabilities in higher education (Smith et al., 2007). All significant findings from our study indicate that students with LD and mental health related disabilities have different profiles. Thus, it stands to reason that there should be a focused approach towards students with mental health related disabilities and what campus professionals can do to facilitate their inclusion in college.

McEwan and Downie (2013) wrote, “As compared to LD students, the profile of PD (psychiatric disability) students that emerged from this study is one of marginalization- students functioning on the periphery of the established disability support system" (p. 239). Given that students with mental health related disabilities in our study were less likely to register for campus disability services, therapists and campus professionals need to collaborate on how to best help these students in pursuing their studies. Working in isolation, campus disability service providers may lack both a depth of understanding of the specific perspective student as well as the more general needs of students with a variety of mental health related disabilities.

For example, due to the fluctuating nature of mental health related disabilities, students may feel that many of the services and accommodations commonly offered through the office for students with disabilities, such as extended time on exams and note-takers for lectures, will not be helpful or relevant. Their needs may be more closely related to their inability to regularly attend classes when they are experiencing mental health related symptoms or when experiencing medication change side-effects. Accommodations that may be more appropriate and beneficial for these students include quiet spaces, alternate times for exams, online courses, extensions of deadlines for assignments, virtual office hours (e.g., Skype), class notes and handouts online, submitting assignments online and video recording of classes that students can view any time.

Collins \& Mowbray (2005) found that fear of being stigmatized was a key barrier that prevented students with mental health related disabilities from registering for campus disability services. This fear could be minimized by assuring students that professors will not be given access to their diagnosis and by indicating that accommodations will be based on students' needs rather than on the diagnosis.

Raymond (2012) gave an example of using a needs based approach to address fatigue and significant lack of energy for some students with mental health related disabilities by suggesting strategies for the student and the campus disability service provider, such as keeping a to-do list, ensuring long enough breaks between classes, giving students extended time for assignments, and a room to rest in if necessary. Instructors have no reason to be informed of a diagnosis, but would probably benefit from understanding the relationship between a student's needs and the required accommodations, such as flexibility in attendance policies.

As feelings of alienation on campus were seen to be a significant problem for students with mental health related disabilities this, too, needs to be addressed in a systemic manner. Liaison with community-based mental health professionals may be a first step in reducing feelings of social alienation on campus. Some organizations can support and accompany students with mental health related disabilities in the pursuit of their studies by offering services, including an individual who can accompany the student on campus to help them adapt, guiding students in the development of a plan to succeed academically, and encouraging the student to recognize their strengths and competences. Some students transition best by registering for the minimum number of courses permitted, which allows them not only to refresh their academic skills but also their social-emotional skills. Given that social alienation on campus and the school environment are key determinants of academic persistence, strategies to reduce the stigma of mental illness at the institutional level are needed.

Students with mental health related disabilities are a group that is both understudied and underserved. Future research should focus on developing a more comprehensive understanding of how to eliminate the barriers that students with mental health related disabilities encounter when pursuing college, and on how to best facilitate their academic success.

\section{Acknowledgements}

This study was funded by the Social Sciences and Humanities Research Council of Canada (SSHRC). We are 
grateful for their support.

\section{References}

Ajzen, I. (2002). Perceived behavioral control, self-efficacy, locus of control, and the theory of planned behavior. Journal of Applied Social Psychology, 32(4), 665-683. https://doi.org/10.1111/j.1559-1816.2002.tb00236.x

American Psychiatric Association. (2013). DSM-IV. Arlington, Virginia : Author.

Ardell, S., Beug, P., \& Hrudka, K. (2016). Perceived stress levels and support of student disability services. University of Saskatchewan Undergraduate Research Journal, 2(2). Retrieved from http://usurj.journalhosting.ucalgary.ca/usurj/index.php/usurj/article/view/150/pdf

Becker, S., \& Palladino, J. (2016). Assessing faculty perspectives about teaching and working with students with disabilities. Journal of Postsecondary Education and Disability, 29(1), 65-82.

Belch, H. A. (2011). Understanding the experiences of students with psychiatric disabilities: A foundation for creating conditions of support and success. New Directions for Student Services, 134, 73-94. https://doi.org/10.1002/ss.396

Blanco, C., Okuda, M., Wright, C., Hasin, D.S., Grant, B.F., Liu, S-M., \& Olfson, M. (2008). Mental health of college students and their non-college-attending peers. Archives of General Psychiatry, 65(12), 1429-1437. https://doi.org/10.1001/archpsyc.65.12.1429

Capozzi, F., Casini, M. P., Romani, M., De Gennaro, L., Nicolais, G., \& Solano, L. (2008). Psychiatric comorbidity in learning disorder: Analysis of family variables. Child Psychiatry \& Human Development, 39(1), 101-110. https://doi.org/10.1007/s10578-007-0074-5

Collins, K. D., \& Mowbray, C. T. (2005). Higher education and psychiatric disabilities: National survey of campus disability services. American Journal of Orthopsychiatry, 75(2), 304-315. https://doi.org/10.1037/0002-9432.75.2.304

DaDeppo, L. M. W. (2009). Integration factors related to the academic success and intent to persist of college students with learning disabilities specific learning disorder. Learning Disabilities Research \& Practice, 24(3), 122-131. https://doi.org/10.1111/j.1540-5826.2009.00286.x

Dong, S., \& Lucas, M. S. (2013). An analysis of disability, academic performance, and seeking support in one university setting. Career Development and Transition for Exceptional Individuals. Advance online publication. https://doi.org/10.1177/2165143413475658

Dong, S., \& Lucas, M. S. (2016). An analysis of disability, academic performance, and seeking support in one university setting. Career Development and Transition for Exceptional Individuals, 39(1), 47-56. https://doi.org/10.1177/2165143413475658

Eisenberg, D., Golberstein, E., \& Gollust, S. F. (2007). Help-seeking and access to mental health care in a university student population. Medical Care, 45(7), 594-601. https://doi.org/10.1097/MLR.0b013e31803bb4c1

Eisenberg, D., Golberstein, E., \& Hunt, J.B. (2009). Mental health and academic success in college. The B.E. Journal of Economic Analysis \& Policy, 9(1). https://doi.org/10.2202/1935-1682.2191

Fichten, C . S., Heiman, T., Jorgensen, M., Nguyen, M. N., Havel, A., King, L., Budd, J., \& Amsel, R. (2016). Theory of Planned Behavior predicts graduation intentions of Canadian and Israeli postsecondary students with and without learning disabilities / attention deficit hyperactivity disorder. International Journal of Higher Education, 5(1), 208-219. https://doi.org/10.5430/ijhe.v5n1p208

Fichten, C. S., Jorgensen, S., Havel, A., Barile, M. (2006). College students with disabilities: Their future and success - Final report presented to FQRSC. Montréal: Adaptech Research Network, Dawson College. Retrieved from ERIC database. (ED491585)

Fichten, C. S., Nguyen, M. N., King, L., Havel, A., Mimouni, Z., Barile, M., Budd, J., ... Gutberg, J. (2014a). How well do they read? Brief English and French screening tools for college students. International Journal of Special Education, 29(1), 33-46.

Fichten, C.S., Nguyen, M.N., Amsel, R., Jorgensen, S., Budd, J., Jorgensen, M., . . Barile, M. (2014b). How well does the Theory of Planned Behavior predict graduation among college and university students with disabilities? Social Psychology of Education, 17(4), 657-685. https://doi.org/10.1007/s11218-014-9272-8 
Fossey, E., Chaffey, L., Venville, A., Ennals, P., Douglas, J., \& Bigby, C. (2017). Navigating the complexity of disability support in tertiary education: Perspectives of students and disability service staff. International Journal of Inclusive Education. Advance online publication. https://doi.org/10.1080/13603116.2017.1278798

Gosselin, M. \& Ducharme, R. (2017). Détresse et anxiété chez les étudiants du collégial et recours aux services d'aide socioaffectifs. Revue Service Social, 63(1), 92-104. https://doi.org/10.7202/1040048ar

Harrison, A. G., \& Holmes, A. (2012). Easier said than done: Operationalizing the diagnosis of learning disability for use at the postsecondary level in Canada. Canadian Journal of School Psychology, 27, 12-34. https://doi.org/10.1177/0829573512437021

Harrison, A. G., \& Wolforth, F. (2012). Findings from a pan-Canadian survey of disability services providers in postsecondary education. International Journal of Disability, Community \& Rehabilitation, 11(1).

Holmes, A., \& Silvestri, R. (2015). Rates of mental illness and associated academic impacts in Ontario's college students. Canadian Journal of School Psychology. Advance online publication. https://doi.org/10.1177/0829573515601396

Jorgensen, S., Fichten, C. S., Havel, A., Lamb, D., James, C., \& Barile, M. (2005). Academic performance of college students with and without disabilities: An archival study. Canadian Journal of Counselling, 39(2), 101-117.

Kay, J. (2010). The rising prominence of college and university mental health issues. In J. Kay \& V. Schwartz (Eds.), Mental health care in the college community (pp. 1-20). Dayton, Ohio: John Wiley \& Sons, Ltd. https://doi.org/10.1002/9780470686836.ch1

Kessler, R. C., Foster, C. L., Saunders, W. B., \& Stang, P. E. (1995). Social consequences of psychiatric disorders, I: Educational attainment. American Journal of Psychiatry, 152(7), 1026-1032. https://doi.org/10.1176/ajp.152.7.1026

Kim, W. H., \& Lee, J. (2016). The effect of accommodation on academic performance of college students with disabilities. Rehabilitation Counseling Bulletin, 60(1), 40-50. https://doi.org/10.1177/0034355215605259

Knight, W., Wessel, R. D., \& Markle, L. (2016). Persistence to graduation for students with disabilities: Implications for performance-based outcomes. Journal of College Student Retention. Advance online publication. https://doi.org/10.1177/1521025116632534

Koch, L. C., Mamiseishvili, K., \& Higgins, K. (2014). Persistence to degree completion: A profile of students with psychiatric disabilities in higher education. Journal of Vocational Rehabilitation, 40, 73-82. https://doi.org/10.3233/JVR-130663

Lyman, M., Beecher, M. E., Griner, D., Brooks, M., Call, J., \& Jackson, A. (2016). What keeps students with disabilities from using accommodations in postsecondary education? A Qualitative review. Journal of Postsecondary Education and Disability, 29(2), 131-140.

Margari, L., Buttiglione, M., Craig, F., Cristella, A., de Giambattista, C., Matera, E., ... \& Simone, M. (2013). Neuropsychopathological comorbidities in learning disorders. BMC Neurology, 13, 198-203. https://doi.org/10.1186/1471-2377-13-198

McEwan, R.C. \& Downie, R. (2013). College success of students with psychiatric disabilities: Barriers of access and distraction. Journal of Postsecondary Education \& Disability, 26(3), 233-245.

McGregor, K. K., Langenfeld, N., Horne, S. V., Oleson, J., Anson, M., \& Jacobson, W. (2016). The university experiences of students with learning disabilities. Learning Disabilities Research \& Practice, 31(2), 90-102. https://doi.org/10.1111/ldrp.12102

Mowbray, C. T., Bybee, D., \& Collins, M. E. (2001). Follow-up client satisfaction in a supported education program. Psychiatric Rehabilitation Journal, 24(3), 237-247. https://doi.org/10.1037/h0095088

Murphy, E. (2017). Responding to the needs of students with mental health difficulties in higher education: An Irish perspective. European Journal of Special Needs Education, 32(1), 110-124. https://doi.org/10.1080/08856257.2016.1254966

Raymond, O. (2012, November). Évaluation des besoins en contexte collégial. Presentation at the Journée des répondants. Québec. 
Salzer, M. S., Wick, L. C., \& Rogers, J. A. (2008). Familiarity with and use of accommodations and supports among postsecondary students with mental illnesses. Psychiatric Services, 59, 370-375. https://doi.org/10.1176/appi.ps.59.4.370

Smith, S. G., English, R., \& Vasek, D. (2002). Student and parent involvement in the transition process for college freshmen with learning disabilities. College Student Journal, 36(4), 491-503.

Smith, T. B., Dean, B., Floyd, S., Silva, C., Yamashita, M., Durtschi, J., \& Heaps, R. A. (2007). Pressing issues in college counseling. Journal of College Counseling, 10(1), 64-78. https://doi.org/10.1002/j.2161-1882.2007.tb00007.x

Snyder, T. D., \& Dillow, S. A. (2012). Digest of education statistics 2011[ NCES 2012-001]. Washington, DC: National Center for Education Statistics, Institute of Education Sciences, U.S. Department of Education. Retrieved from http://nces.ed.gov/pubs2012/2012001.pdf

Solberg, V. S., Gusavac, N., Hamann, T., Felch, J., Johnson, J., Lamborn, S., \& Torres, J. (1998). The adaptive success identity plan (ASIP). Career Development Quarterly, 47(1), 48-95. https://doi.org/10.1002/j.2161-0045.1998.tb00728.x

St-Onge, M., Tremblay, J., \& Garneau, D. (2009). L'offre de services pour les étudiants des cégeps ayant des problèmes de santé mentale ou un trouble mental. Rapport final de recherche présenté à la Direction des affaires étudiantes universitaires et collégiales (DAEUC) du ministère de l'Éducation, du Loisir et du Sport (MELS).

Storrie, K., Ahern, K., \& Tuckett, A. (2010). A systematic review: Students with mental health Problems - A growing problem. International Journal of Nursing Practice, 16(1), 1-6. https://doi.org/10.1111/j.1440-172X.2009.01813.x

Tinto, V. (1975). Dropout from higher education: A theoretical synthesis of recent research. Review of Educational Research, 45(1), 89-125. https://doi.org/10.3102/00346543045001089

Tinto, V. (1993). Leaving college: Rethinking the causes and cures of student attrition. (2nd ed.). Chicago: University of Chicago Press.

Venville, A. Street, A. \& Fossey, E. (2014). "Good intentions: Teaching and specialist support staff perspectives of student disclosure of mental health issues in post-secondary education." International Journal of Inclusive Education 18(11), 1172-1188. https://doi.org/10.1080/13603116.2014.881568

Wagner, M., Newman, L., Cameto, R., Garza, N., \& Levine, P. (2005). After high school: A first look at the postschool experiences of youth with disabilities: A report from the National Longitudinal Transition Study-2 (NLTS2). U.S. Department of Education. Retrieved from http://www.nlts2.org/reports/2005_04/nlts2_report_2005_04_execsum.pdf

Wiseman, R. L., Emry, R. A., \& Morgan, D. (1988). Predicting academic success for disabled students in higher education. Research in Higher Education, 28(3), 255-269. https://doi.org/10.1007/BF00992234 


\section{Appendix}

\section{COLLEGE / UNIVERSITY EXPERIENCE QUESTIONNAIRE (CEQ)}

Using the following scale, indicate in what way each of the items below has affected your postsecondary studies
by making them harder or easier:
$\begin{array}{ccccccc}\mathbf{1} & \mathbf{2} & \mathbf{3} & \mathbf{4} & \mathbf{5} & \mathbf{6} & \text { [ N/A ] } \\ \text { Much } & \text { Moderately } & \text { Slightly } & \text { Slightly } & \text { Moderately } & \text { Much } & \text { Not } \\ \text { Harder } & \text { Harder } & \text { Harder } & \text { Easier } & \text { Easier } & \text { Easier } & \text { Applicable }\end{array}$

Put a number beside all items. If an item is not applicable to you, respond with N/A (not applicable).

\section{Personal Situation}

1._ Financial situation

2. Having paid employment

3. ___ Family situation

4. ___ Having friends

5.___ Level of personal motivation

6.___ Study habits

7.___ Previous education experiences

8. Health

9. ___ Impact of my disability

\section{School Environment}

10._L Level of difficulty of courses

11.___ Course load

12._Course schedule

13._Attitudes of professors

14.___ Attitudes of non-teaching staff (e.g., registration staff, financial aid staff)

15._Attitudes of students

16.___ Availability of computers on campus

17._ Training on computer technologies on campus

18.___ Availability of course materials

19.___ Opportunity to participate in school extracurricular activities (e.g., clubs, sports, social activities)

20._Willingness of professors to adapt courses to my needs

21.___ Accessibility of building facilities (e.g., doorways, classrooms, labs)

22.___ Accessibility of school physical education courses

23.___ Availability of disability related services on Campus 